\title{
JPMI \\ MENINGKATKAN KEMAMPUAN KOMUNIKASI MATEMATIK SISWA SMP DENGAN PENDEKATAN CONTEXTUAL TEACHING AND LEARNING (CTL)
}

\author{
Juliana Safitri ${ }^{1}$, Luvy Sylviana Zanthy ${ }^{2}$, Heris Hendriana ${ }^{3}$ \\ 1,2,3 IKIP Siliwangi \\ 1julianasftr@yahoo.co.id, ${ }^{2} z a n t h y l u v y @ i k i p s i l i w a n g i . a c . i d,{ }^{3}$ herishen@ikipsiliwangi.ac.id
}

\begin{abstract}
This research did from the low ability phenomena of mathematical communication of SMP in Purwakarta. The low skill ability of mathematical communication can be seen from the lack of students in completing the test of mathematical communication form to provided in the first research, the purpose of this research was to examined the improvement of CTL (Contextual Teaching and Learning) skill with traditional learning and the methodology of this research using quasi experimental method which consist of two classes. The first is experiment class treated using CTL and the second is control class treated traditional learning. The population of the research taken were students of SMP Negeri 1 Babakan Cikao and randomly selected sample of consist from 30 students of class VII A as experiment. Class and 30 students of class VII D as control class. The instrument of this research used 6 items about mathematical communication description form, that has been tested the validity, reliability and distinguish of power form indexed difficulty. Based on the result of data analysis have conclude that the improvement of mathematical communication ability in SMP Negeri 1 Babakan Cikao by using CTL approach is better than traditional learning.
\end{abstract}

Keywords: Mathematical Communication, CTL approach

\begin{abstract}
Abstrak
Penelitian ini dilakukan karena minimnya kemampuan komunikasi matematik siswa SMP di Purwakarta. Rendahnya kemampuan komunikasi matematik dapat dilihat dari minimnya kemampuan siswa dalam menyelesaikan tes berupa soal kemunikasi matematik yang diberikan pada studi awal penelitian. Maksud penelitian ini dilakukan yakni untuk mengkaji peningkatan kemampuan komunikasi matematik siswa yang pembelajaran menggunakan pendekatan CTL dengan pembelajaran biasa. Metode penelitian yang dipakai adalah metode kuasi eksperimen, dimana terdiri dari dua kelas yakni kelas eksperimen diberi perlakuan menggunakan pendekatan CTL, sedangkan kelas kontrol yakni kelas yang diberi perlakuan dengan pembelajaran biasa. Adapun populasi yang diambil dalam penelitian ini adalah Siswa SMPN 1 Babakan Cikao dan sampel dipilih secara acak yakni 30 siswa kelas VII.A sebagai kelas eksperimen, sedangkan 30 siswa kelas VII.D sebagai kelas kontrol. Instrumen yang digunakan berupa 6 butir soal komunikasi matematik berbentuk uraian yang telah diuji validitas, reabilitas, daya pembeda dan tingkat kesukaran. Berdasarkan hasil analisis data, dapat disimpulkan bahwa peningkatan kemampuan komunikasi matematik siswa SMP yang memperoleh pembelajaran menggunakan pendekatan CTL lebih baik daripada pembelajaran biasa.
\end{abstract}

Kata Kunci: Komunikasi Matematik, Pendekatan CTL

How to cite: Safitri, J., Zanthy, L. S., \& Hendriana, H. (2018). Meningkatkan Kemampuan Komunikasi Matematik Siswa SMP dengan Pendekatan Contextual Teaching and Learning (CTL). JPMI - Jurnal Pembelajaran Matematika Inovatif, 1 (4), 575-582. 


\section{PENDAHULUAN}

Matematika merupakan ilmu pengantar yang dilibatkan dalam masalah kehidupan sehari-hari maupun disiplin ilmu lainnya. Tak heran bahwa matematika adalah ilmu dasar yang harus siswa kuasai sebagai pengantar aktivitas sehari-hari, memandang kehidupan yang kompetitif, dinamis dan terus berkembang.

Pentingnya memahami matematika di sekolah ditekankan pada proses pembelajaran, yang bertujuan agar siswa dapat memahami konsep yang dipelajari, serta mampu menyelesaikan masalah berdasarkan konsep, sehingga aktivitas belajar matematika lebih bermakna bagi siswa dan dapat memberikan bekal keterampilan yang memadai di kehidupan sehari-hari. Namun Zanthy (2014) mengungkapkan bahwa baik pada siswa tingkat sekolah dasar hingga perguruan tinggi, matematika adalah sesuatu yang menakutkan dan pembelajaran matematika yang diperoleh di kelas tidaklah memiliki keterkaitan dengan kehidupan sehari-hari. Maka dari itu, perlu suatu kemampuan yang mampu menekankan dan meningkatkan keterampilan siswa untuk menerima maupun menyampaikan informasi yang berkaitan dengan ilmu matematika, terutama berupa ide-ide matematika yang abstrak yang pada akhirnya bisa diterapkan ketika siswa menghadapi masalah matematik di kehidupan sehari-hari.

Namun studi pendahuluan yang dilakukan Safitri (2017) menunjukkan bahwa kemampuan komunikasi matematik siswa masih tergolong rendah. Berdasarkan studi tersebut dengan subjek beberapa siswa di SMPN 1 Babakan Cikao Purwakarta menunjukkan bahwa kemampuan komunikasi matematik siswa masih rendah. Hal itu terlihat dari kurang lengkapnya langkahlangkah penyelesaian siswa terhadap soal yang melibatkan model-model matematika, bahkan ada beberapa siswa yang tidak menjawab soal tersebut. Mereka berasumsi bahwa, soal yang melibatkan model-model matematik sulit dipahami, bahkan tidak tertarik terutama jika harus mengomunikasikan simbol-simbol matematik. Kemudian menurut studi yang dilakukan Hendriana, Sumarmo \& Rohaeti (2016) menemukan bahwa ada beberapa kesulitan berkenaan dengan komunikasi matematis yakni dalam menyusun pertanyaan dari suatu kasus dan bagaimana menyelesaikannya. Hal tersebut menunjukkan bahwa kemampuan komunikasi merupakan kemampuan yang harus dikembangkan mengingat bahwa dalam menyelesaikan masalah sehari-hari yang melibatkan simbol dan ide matematik, dan kemampuan tersebut memiliki hubungan yang erat dengan disiplin ilmu lainnya. Sejalan dengan pernyataan Hendriana (2009) bahwa komunikasi matematis banyak digunakan dalam beragam konten matematika dan bidang studi lainnya.

Komunikasi matematik penting dikuasai karena dapat disebut sebagai perantara untuk membantu siswa dalam menyusun langkah-langkah penyelesaian masalah berupa bahasa matematik, membangun pola pikir siswa, dan terampil dalam menyelesaikan masalah matematik yang lebih kompleks di dunia nyata (Hidayat, \& Sumarmo, 2013; Rahmi, Nadia, Hasibah, \& Hidayat, 2017; Zakiah, Saomi, Syara, Hidayat, \& Hendriana, 2018). Menurut NCTM (Hendriana, Soemormo \& Rohaeti, 2017) menyatakan bahwa komunikasi perlu dikembangkan karena ada beberapa tujuan yang harus dicapai; a) mengorganisasikan dan menggabungkan cara berpikir matematik, belajar konsep baru dengan cara menggambar objek, menggunakan diagram, menulis, dan menggunakan simbol matematis; b) mengomunikasikan pemikiran matematika secara logis dan jelas sehingga mudah dimengerti; c) menganalisis dan mengevaluasi pemikiran matematik dan strategi lain, berkesplorasi mencari cara dan strategi lain dalam menyelesaikan masalah, dan d) menggunakan bahasa matematik untuk mengekspresikan ide-ide dengan benar. 
Salah satu kompetensi yang harus dikembangkan siswa yaitu mampu mengembangkan bahasa matematik yang mereka punya sehingga siswa dapat mengomunikasikan gagasan-gagasan matematik dalam suatu ide matematika. Oleh karena itu, dibutuhkan pembelajaran yang mempunyai karakteristik yang dapat membangun gagasan-gagasan tersebut serta dapat menumbuhkan kondisi pembelajaran yang aktif dan inovatif. Pembelajaran yang inovatif sangat baik diterapkan dalam upaya meningkatkan pembelajaran matematik, salah satunya adalah pendekatan CTL atau kontekstual. Pendekatan CTL merupakan cara lain yang dapat diterapkan untuk meningkatkan pembelajaran lebih inovatif. Pemodelan yang ada pada pendekatan CTL mengharuskan siswa untuk terampil memberikan model tertentu mengenai materi terkait sehingga pembelajaran akan lebih bermakna. Ketika melakukan pemodelan, diharapkan siswa mampu memusatkan keterampilan akademis yang mereka miliki sehingga mampu diimplementasikan dalam ranah dunia nyata untuk suatu tujuan yang bermakna.

Aktivitas belajar dalam pendekatan ini pun mengharuskan siswa untuk turut serta dalam suatu aktivitas belajar, dimana di dalamnya siswa bisa saling berinteraksi sosial dalam menyelesaikan soal, berbagi pendapat dan pengetahuan mereka mengenai keterampilan kognitif yang mereka punya masing-masing, sehingga siswa berperan banyak dalam proses pembelajaran. Memperhatikan karakteristik komunikasi matematik dengan pendekatan CTL, maka pendekatan tersebut memungkinkan dapat meningkatkan kemampuan komunikasi matematik siswa. Sehingga penulis berminat untuk melaksanakan penelitian dengan judul "Meningkatkan Kemampuan Komunikasi Matematis Siswa SMP dengan Pendekatan Contextual Teaching and Learning".

Berdasarkan uraian latar belakang tersebut, maka penelitian ini dilakukan bertujuan untuk menelaah apakah peningkatan kemampuan komunikasi matematis yang pembelajaran menggunakan pendekatan CTL lebih baik dari yang memperoleh pembelajaran biasa?

Dengan dilakukan penelitian ini, diharapkan dapat memberikan manfaat bagi guru dan siswa, diantaranya:

1) Bagi guru, diharapkan dapat menjadi inovasi dan dapat memotivasi guru agar model pembelajaran yang diterapkan lebih variatif dan inovatif

2) Bagi siswa, diharapkan dapat menambah semangat belajar dan keterampilan siswa sehingga dapat meningkatkan komunikasi matematis. Pembelajaran dengan menggunakan pendekatan CTL diharapkan mampu membantu siswa untuk menemukan solusi dari permasalahan sehari-hari yang disajikan dengan ide matematika yang abstrak sehingga

3) mampu diimplementasikan dalam kehidupan sehari-hari.

Bagi peneliti, merupakan pengalaman berharga sehingga menjadi pertimbangan untuk mengembangkan kemampuan komunikasi matematis dalam bidang matematika maupun terhadap ilmu terapan lainnya.

\section{METODE}

Penelitian ini dilakukan dalam bentuk penelitian eksperimen. Dengan desain penelitian (Ruseffendi, 2005) sebagai berikut:
A $\quad \mathrm{O} \quad \mathrm{X} \quad \mathrm{O}$
A $\mathrm{O} \quad \mathrm{O}$ 
Keterangan :

A : Pengelompokan sampel secara acak kelas

$\mathrm{O}:$ Pretes $=$ Postes tes kemampuan komunikasi mmatematik

$\mathrm{X}$ : Pembelajaran dengan pendekatan CTL

Populasi yang dipilih adalah siswa kelas VII SMPN 1 Babakan Cikao, kemudian sampel dipilih dua kelas secara acak yaitu kelas VII A sebagai kelas eksperimen dan kelas VII D sebagai kelas kontrol. Kelas eksperimen mendapatkan perlakuan tertentu yakni menggunakan pendekatan CTL, sedangkan kelas kontrol diberikan perlakuan menggunakan pembelajaran biasa. Instrumen tes kemampuan komunikasi matematis siswa disusun mengacu pada indikator komunikasi matematis yang telah ditentukan serta mengikuti prosedur yang telah ditentukan. Instrumen yang digunakan berupa tes uraian sebanyak 6 butir soal. Tes yang dilakukan dalam penelitian ini diberikan kepada kelas eksperimen dan kelas kontrol yakni masing-masing sebanyak dua kali. Tes yang dilakukan sebelum materi diberikan pretes bertujuan untuk mengetahui kemampuan awal siswa, sedangkan postes bertujuan untuk melihat hasil pembelajaran siswa setelah mendapatkan perlakuan yang selanjutnya akan diolah sesuai prosedur penelitian.

Adapun contoh instrumen yang digunakan dalam penelitian disajikan pada gambar di bawah ini.

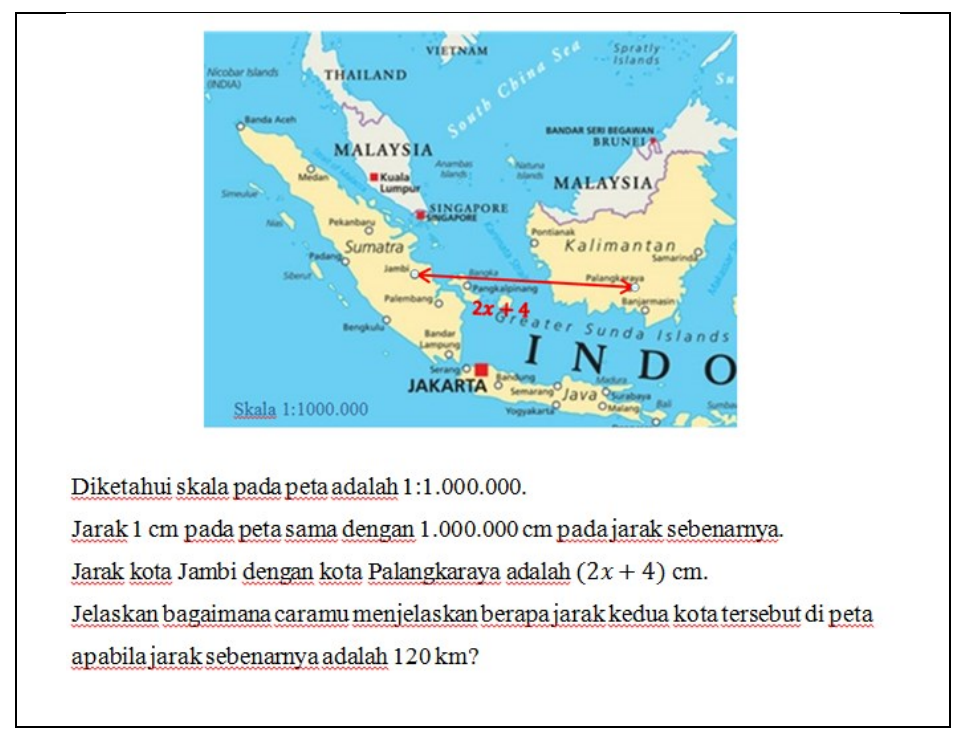

Gambar 1. Instrumen tes tentang kemampuan komunikasi matematis

\section{HASIL DAN PEMBAHASAN}

\section{Hasil}

Penelitian Pengolahan data dibantu oleh Microsoft Office Excel 2010 dan SPSS 21.0.

Berikut ini adalah hasil uji data pretes, postes dan gain yang ternormalisasi untuk mengetahui nilai rata-rata $(\bar{x})$ dan deviasi standar $(s)$. 
Tabel 1. Rekapitulasi Hasil Uji Statistik Kemampuan Komunikasi Matematis

\begin{tabular}{|c|c|c|c|c|c|c|c|}
\hline \multirow[t]{2}{*}{$\begin{array}{l}\text { Kemampuan } \\
\text { Matematik }\end{array}$} & & \multicolumn{3}{|c|}{ Kelas Eksperimen } & \multicolumn{3}{|c|}{ Kelas Kontrol } \\
\hline & & Pretes & Postes & $\begin{array}{l}\mathrm{N}- \\
\text { Gain }\end{array}$ & Pretes & Postes & $\begin{array}{l}\mathrm{N}- \\
\text { Gain }\end{array}$ \\
\hline \multirow{5}{*}{$\begin{array}{l}\text { Komunikasi } \\
\text { Matematis }\end{array}$} & $\mathrm{N}$ & 30 & 30 & 30 & 30 & 30 & 30 \\
\hline & $\mathrm{X}$ maks & 14 & 58 & 0,87 & 13 & 55 & 0,82 \\
\hline & $\mathrm{X} \min$ & 2 & 23 & 0,26 & 0 & 16 & 0,14 \\
\hline & $\bar{x}$ & 6,43 & 42,8 & 0,61 & 5,83 & 32,07 & 0,44 \\
\hline & $s$ & 3,09 & 10 & 0,17 & 3,49 & 11,34 & 0,18 \\
\hline
\end{tabular}

Berdasarkan Tabel 1, dapat dilihat bahwa nilai rata-rata postes dan $\mathrm{N}$-gain kelas yang mendapatkan perlakuan lebih besar dari kelas yang menggunakan pembelajaran biasa.

Tabel 2. Rekapitulasi Hasil Uji Mann Whitney data Pretes Kemampuan Komunikasi

\begin{tabular}{lll}
\hline & Asymp. Sig. (2-tailed) & Keputusan \\
\hline Pretes & 0,456 & $\mathrm{H}_{0}$ diterima \\
$\begin{array}{l}\text { Komunikasi } \\
\text { Matematis }\end{array}$ & \\
\hline
\end{tabular}

Setelah diuji normalitas, data dinyatakan tidak berdistribusi normal. Lalu dilanjutkan dengan uji non-parametrik Mann Whitney U, dapat dilihat bahwa nilai dari Asymp. Sig. (2-tailed) lebih dari $\alpha=0,05$ maka $\mathrm{H}_{0}$ diterima sehingga tidak terdapat perbedaan yang signifikan kemampuan komunikasi matematis antara kelas eksperimen dengan kelas kontrol.

Tabel 3. Rekapitulasi Hasil Uji T Data Postes dan N-Gain Kemampuan Komunikasi

\begin{tabular}{lll}
\hline & Asymp. Sig. (2-tailed) & Keputusan \\
\hline $\begin{array}{l}\text { Kostes } \\
\text { Komunikasi }\end{array}$ & 0,000 & $\mathrm{H}_{0}$ ditolak \\
\hline $\begin{array}{l}\text { N-Gain } \\
\text { Komunikasi } \\
\text { Matematis }\end{array}$ & 0,000 & $\mathrm{H}_{0}$ ditolak \\
\hline
\end{tabular}

Setelah dilakukan uji normalitas, didapat bahwa data berdistribusi normal. Kemudian dilakukan uji homogenitas dan uji $\mathrm{T}$ untuk mengukur pencapaian dan peningkatan kemampuan komunikasi matematis siswa. Berdasarkan Tabel 2, dapat dilihat bahwa nilai Asymp. Sig. (2tailed) adalah 0,000, dan asymp. Sig. (1-tailed) adalah kurang dari $\alpha=0,05$ sehingga dapat 
disimpulkan bahwa pencapaian dan peningkatan kemampuan komunikasi matematis siswa kelas eksperimen lebih baik dari kelas kontrol.

\section{Pembahasan}

Berdasarkan hasil penelitian terhadap siswa SMPN 1 Babakan Cikao diperoleh bahwa kemampuan komunikasi yang menggunakan pembelajaran CTL lebih baik dibanding dengan yang menggunakan pembelajaran biasa. Pada awalnya siswa dibangun terlebih dahulu semangat maupun motivasi belajarnya sehingga siswa berminat untuk mengembangkan dan menemukan pemahamannya sendiri mengenai materi perbandingan melalui pengalamannya dalam kehidupan nyata. Sejalan dengan teori Bruner (Lestari \& Yudhanegara, 2015) bahwa proses belajar akan berjalan dengan baik dan kreatif jika guru memberikan kesempatan pada siswa untuk menemukan suatu konsep, teori, aturan atau pemahaman melalui konten yang dijumpai dalam kehidupan nyata. Setelah siswa dapat mengonstruksikan pengetahuannya, siswa diberikan kesempatan untuk berperan aktif pada saat pembelajaran dengan kelompok belajarnya maupun kepada guru sebagai pembimbing. Dalam aktivitas ini keterampilan siswa dikembangkan terutama pada saat berkomunikasi dalam hal bertukar kemampuan kognitif dengan teman sebayanya. Kemudian pada kegiatan modelling yakni kegiatan meniru dimana hal ini membantu siswa untuk meningkatkan pengetahuan tentang keterampilan mereka dalam memecahkan masalah yang berkenaan dengan konteks sehari-hari. Keterampilan tersebut baik dalam aspek kognitif maupun aspek afektif. Peningkatan yang terdapat pada kelas eksperimen dinilai baik dibanding dengan kelas kontrol, namun salahsatu faktor yang menghambat peningkatan tersebut adalah dibutuhkan waktu lebih untuk anak mempelajari dan mengasah keterampilannya pada saat kegiatan modeling, karena setiap anak mempunyai karakteristik yang berbeda-beda dan sebagian besar masih belum terbiasa mengenal simbol-simbol abstrak. Kegiatan tersebut ditujukan agar anak mampu memahami lebih maksud yang telah dipelajari di sekolah, sehingga bisa diterapkan dalam kehidupan sehari-hari. Sejalan dengan hasil penelitian Anggraeni \& Sumarmo (2013) bahwa pembelajaran disarankan dilaksanakan dalam waktu yang cukup untuk memberikan kesempatan siswa belajar secara bermakna.

Berikut hasil jawaban siswa dalam menyelesaikan soal komunikasi matematik yang disajikan dalam gambar 1 dan 2.

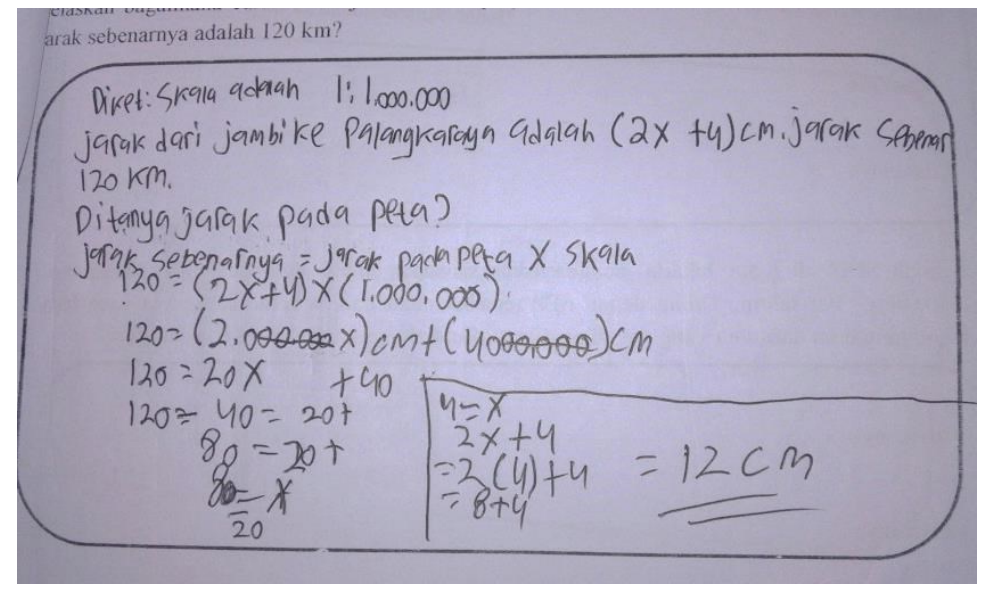

Gambar 1. Jawaban benar dan lengkap 
Berdasarkan gambar 1 terlihat bahwa siswa mengerjakan soal secara sistematis. Langkah awal yang dilakukan siswa yaitu dengan mengidentifikasi terlebih dahulu informasi yang diketahui dalam soal. Kemudian siswa mulai menyusun langkah penyelesaian dengan menggunakan strategi yang berkaitan dengan apa yang ditanyakan. Dalam hal ini siswa mampu menjalankan strategi dengan baik dan benar, dan setelah strategi yang pertama telah diselesaikan, selanjutnya siswa mampu menggunakan strategi yang lainnya agar solusi akhir yang dimaksud tercapai. Hal ini sejalan dengan penelitian Kusdinar, dkk. (2017) yang berpendapat bahwa "dalam proses membuktikan suatu permasalahan, diperlukan kemampuan siswa mulai dari merumuskan ide awal dan menyusun strategi penyelesaian"

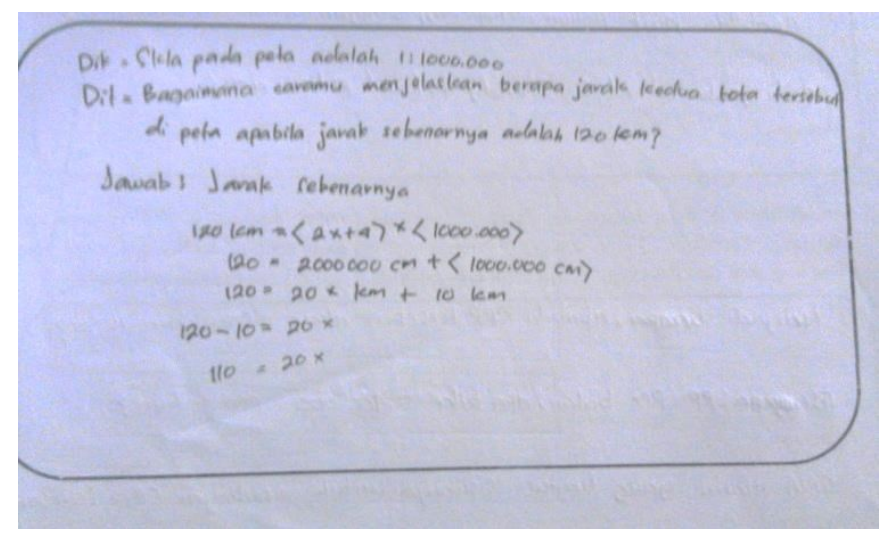

Gambar 2. Jawaban kurang lengkap

Pada gambar 2 terlihat bahwa dalam mengerjakan soal, siswa belum mampu menyelesaikan masalah dengan tepat dan lengkap sesuai dengan yang dimaksud. Meskipun strategi awal yang digunakan siswa sudah dinilai tepat, namun pada tahap pengerjaannya siswa masih mengalami kendala terutama pada saat mengoperasikan model matematik yang disajikan. Kemungkinan lain penyebab hal itu terjadi karena siswa masih belum terbiasa mengoperasikan konsep yang melibatkan bentuk model matematika lainnya, karena pada pembelajaran biasa siswa hanya diperkenalkan dengan konsep matematika yang sederhana. Hal tersebut sejalan dengan penelitian yang dilakukan Anggraeni \& Sumarmo (2013) bahwa tugas komunikasi matematik siswa selain harus memahami konsep juga harus dapat menyatakan konsep yang bersangkutan dalam bentuk matematika lainnya, dan memuat pula tugas menyatakan suatu model matematika ke dalam bentuk masalah sehari-hari. Kemudian pada tahap selanjutnya siswa semakin mengalami kesulitan, dan jawaban yang disajikan hanya seadanya..

\section{KESIMPULAN}

Berdasarkan hasil analisis data dan pembahasan data diatas, dapat disimpulkan bahwa peningkatan kemampuan komunikasi matematis siswa yang mendapatkan pembelajaran CTL lebih baik dari yang menggunakan pembelajaran biasa.

\section{DAFTAR PUSTAKA}

Anggraeni, D., Sumarmo, U. (2013). Meningkatkan Kemampuan Pemahaman dan Komunikasi Matematik Siswa SMK melalui Pendekatan Kontekstual dan Strategi Formulate-ShareListen-Create (FSLC). Infinity, 2(1), 1-12. Retrieved from stkipsiliwangi.ac.id Hendriana, H., Rohaeti, E. E. dan Sumarmo, U. (2017). Hard Skills dan Soft Skills Matematik 
Siswa. Bandung: Refika Aditama.

Hendriana, H., Sumarmo, U., \& Rohaeti, E. E. (2016). Kemampuan Komunikasi Matematik Serta Kemampuan dan Disposisi Berpikir Kritis Matematik. Delta-Pi: Jurnal Matematika Dan Pendidikan Matematika, 2(1).

Hendriana, H. (2009). Pembelajaran dengan Pendekatan Methaphorical Teaching untuk Meningkatkan Kemampuan Pemahaman Matematik, Komunikasi Matematik dan Kepercayaan Diri Siswa Sekolah Pertama. Disertasi Doktor pada PPS UPI Bandung: tidak dipublikasikan

Hidayat, W., \& Sumarmo, U. (2013). Kemampuan Komunikasi dan Berpikir Logis Matematika serta Kemandirian Belajar. dalam Jurnal Delta-fi, 2(1).

Kusdinar, U., Sukestiyarno, S., Isnarto, I., \& Istiandaru, A. (2017). Krulik And Rudnik Model Heuristic Strategy In Mathematics Problem Solving. International Journal On Emerging Mathematics Education, 1(2), 205-210.

Lestari, K. E., \& Yudhanegara, M. R. (2015). Penelitian Pendidikan Matematika. Bandung: Refika Aditama.

Rahmi, S., Nadia, R., Hasibah, B., \& Hidayat, W. (2017). The Relation between Self-Efficacy toward Math with the Math Communication Competence. Infinity Journal, 6(2), 177-182.

Ruseffendi, E. T. (2005). Dasar-Dasar Penelitian Pendidikan \& Bidang Non-Eksakta Lainnya. Bandung: PT Tarsito.

Safitri, J. (2017). Prosiding Seminar Nasional Matematika dan Pendidikan Matematika. In Analisis Kemampuan Komunikasi Matematis siswa SMP Kelas VII dalam menyelesaikan Soal Himpunan (p. 1263). Bandung: STKIP Siliwangi Bandung. Retrieved from stkipsiliwangi.ac.id

Zakiah, L., Saomi, A. S. N., Syara, R., Hidayat, W., \& Hendriana, H. (2018). THE EFFICIENCY OF USING EDUCATION VIDEOS ON THE LINEAR PROGRAM MATERIAL AS OBSERVED IN VOCATIONAL HIGH SCHOOL STUDENTS'MATHEMATICAL COMMUNICATION ABILITY.Journal Of Educational Experts (JEE), 1(1), 11-18.

Zanthy, L. S. (2014). Prosiding Seminar Nasional Matematika dan Pendidikan Matematika. In Nilai Edukasi dan Modifikasi Penerapan Pembelajaran Peluang pada Permainan TekaTeki Sudoku di Sekolah (p. 108). Bandung: STKIP Siliwangi Bandung. Retrieved from stkipsiliwangi.ac.id 